\title{
AUTORIA - NO RISCO DAQUILO QUE ESCAPA À ESTABILIDADE ${ }^{1}$ AUTHORSHIP - AT THE RISK OF ESCAPING FROM STABILITY
}

\author{
Ana Silvia Couto de Abreu
}

Resumo: O processo de autoria é marcado por condições de produção, que se constituem enquanto injunções de diversas ordens, incluindo aí aquilo que falha. Tomamos a regulação da autoria como uma dessas condições de produção, trazendo os embates discursivos e, portanto, politicos que se estabelecem no funcionamento do discurso jurídico, com a produção de apagamentos, preenchimentos do que é tido como furo; embates que se instauram na busca pela estabilização de certos sentidos, envolvendo diversas instâncias da sociedade, sendo que é justamente nesse jogo entre estabilidade e deriva que há deslocamentos possíveis.

Palavras-chave: autoria, discurso, interpretação

Abstract: The authorship process is marked by conditions of production, in which the possibility of failing is included. We recognize the authorship regulation as one of these conditions of production and present discursive confrontations that take place in the functioning of juridical discourse. The confrontations happen in the quest for stabilization of certain senses, involving diverses sectors of society; and displacements are possible precisely between the forces of stability and drift.

Keywords: authorship, discourse, interpretation.

\section{No movimento entre estabilidade e deriva}

Entre estabilidade e deriva o sujeito se constitui, em um movimento nalpela linguagem. Tomar para si sentidos como sendo estáveis, precisos, transparentes é a tentativa de se sentir seguro de si e do

1 Este texto compõe a pesquisa Políticas públicas de autoria no Brasil - uma análise discursiva (FAPESP 2010\52454-7).

2 Professora da Universidade Federal de São Carlos.

Organon, Porto Alegre, n 53, julho-dezembro, 2012, p. 15-25 
mundo, na busca por um controle da situação. Mas o inusitado dos sentidos nos vem a cada formulação, mesmo naquelas que aparentam repetição. E isso porque os sentidos transitam, não absolutamente livres, mas marcados pelas posições discursivas dos sujeitos.

Situamos a autoria nesse campo de embate pela estabilização de determinados sentidos, em um movimento que toma o sujeito, na ousadia de um percurso de produção, cujo resultado lhe é desconhecido de antemão, mas que significa. E, nesse sentido, a autoria constitui-se em um processo de arriscar-se, de se colocar na posição daquele que está à deriva. E aí reside um aspecto contraditório inerente ao processo de produção: luta-se pela estabilidade, mas para isso é preciso perdê-la, questioná-la. Deixar que sentidos se dêem a saber, quase que tomados por eles, que somos, na sequência de significantes que vão formando nosso discurso, indiciando nossa memória discursiva.

Assim, entendemos com Pêcheux (1990, p.56) que um discurso não é uma produção "independente das redes de memória e dos trajetos sociais nos quais ele irrompe", sendo que:

só por sua existência, todo discurso marca a possibilidade de uma desestruturação - reestruturação dessas redes e trajetos: todo discurso é o índice potencial de uma agitação nas filiações sócio-históricas de identificação, na medida em que ele constitui ao mesmo tempo um efeito dessas filiações e um trabalho (mais ou menos consciente, deliberado, construído ou não, mas de todo modo atravessado pelas determinações inconscientes) de deslocamento no seu espaço. (PÊCHEUX, 1990, p.56)

Disso deriva para nós uma compreensão da autoria como um processo de interpretação em constante movimento, situando-a, na esteira de Pêcheux (1990, p.57), como uma produção discursiva que marca uma tomada de posição, como efeito de identificação assumida, potencializando deslocamentos.

Se o real da língua não fosse sujeito à falha e o real da história não fosse passível de ruptura não haveria transformação, não haveria movimento possível, nem dos sujeitos, nem dos sentidos. É porque a língua é sujeita ao equívoco e a ideologia é um ritual com falhas que o sujeito, ao significar, se significa. Por isso, dizemos que a incompletude é a condição da linguagem: nem os sujeitos, nem os sentidos, logo, nem o discurso, já estão prontos e acabados. Eles estão sempre se fazendo, havendo um trabalho contínuo, um movimento constante do simbólico e da história. (ORLANDI, 2000, p. 37)

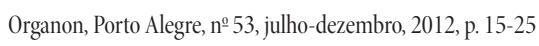


E lidar com isso que falha, falta, suportando a incompletude, na ilusão constante da completude, faz-nos produzir novos e novos textos, compondo uma rede discursiva que traz o outro para nosso campo de sentidos, sempre marcados pelo inconsciente, que não nos deixa nos enganarmos a nós mesmos de todo.

A partir desta posição discursiva, esse processo de autoria é marcado por condições de produção, que se constituem enquanto injunções de diversas ordens, incluindo aí aquilo que falha.

...o sujeito, no momento em que fala e assume o (seu) dizer, produz tanto o seu caminhar quanto os seus tropeços na língua que derivam de contradições e tensões sócio-ideológicas. As névoas de pouca (ou nenhuma) clareza nos movimentos de dizer são, então, constitutivas do sujeito e da língua; se a opacidade é estruturante desse processo de dizer, faz-se necessário levar em conta a existência de que algo falta e padece de sentido, isto é, de uma palavra sempre-escapante, de um não-todo na formulação, de bordas impedidas de serem tocadas e ditas, enfim, de uma esfera de impossível, que está na própria ordem da língua. (ROMÃO, 2011, p.66)

Vivemos, então, imersos em gestos de interpretação, que, embora, aparentem ser frutos de decisões individuais, são marcados pelo coletivo, aqui tomado como símbolo do histórico e político. Orlandi assim situa a injunção à interpretação:

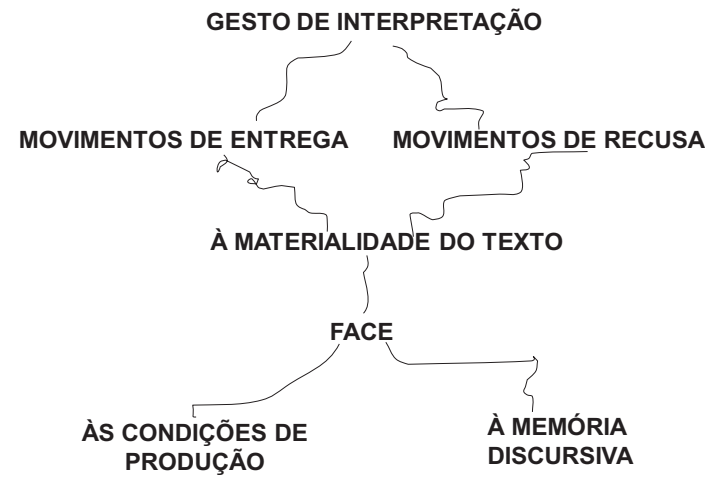

fig. 1. Interpretação (ORLANDI, 1996)

Organon, Porto Alegre, ํำ 53, julho-dezembro, 2012, p. 15-25 
Tomamos a regulação da autoria como uma dessas condições de produção. A regulação se dá em muitos níveis, sendo que destacamos aqui a do campo jurídico, trazendo os embates discursivos e, portanto, políticos que se estabelecem no funcionamento do discurso jurídico, com a produção de apagamentos, preenchimentos do que é tido como furo; embates que se instauram na busca pela estabilização de certos sentidos, envolvendo diversas instâncias da sociedade, sendo que é justamente nesse jogo entre estabilidade e deriva que há deslocamentos possíveis.

\section{Entre restrição e acesso}

A estabilidade de um modelo de produção e circulação de bens culturais e a estabilidade do campo jurídico no que se refere à questão dos direitos autorais são postas em questão, em um momento em que:

Vivemos mudanças nos modos de construção e de circulação de bens culturais, trazendo efeitos quanto a novas possibilidades de acesso a esses bens. De um modelo centrado na relação editor e autor, temos agora maneiras de produzir e fazer circular uma obra que implicam diferentes relações de mediação, surgindo outros envolvidos no processo - o webmaster e o provedor, para ficar em alguns exemplos.

Entendemos, assim, que os sentidos de Direitos Autorais instituídos por leis, acordos e tratados nacionais e internacionais estão em movimento, em um confronto entre regulação e transgressão. Esse confronto coloca às vistas um jogo de forças entre discursividades, como a do copyright e a do copyleft, passando por outras não tão visíveis, mas fortemente presentes na sociedade; esse entrecruzamento de discursividades em conflito atinge o atual modelo brasileiro de garantias ao autor, no que se refere, especialmente, aos seus direitos quanto à reprodução de sua obra. (ABREU, 2009, p.1)

Apresentamos, a seguir, três recortes desse embate no campo das questões do direito autoral.

\section{Recorte 1. Carta de São Paulo pelo acesso a bens culturais}

Nós acadêmicos, artistas, escritores, professores, editores e membros da sociedade civil abaixo assinados, movidos pela convicção quanto à necessidade de promover a universalização do acesso a obras literárias,

Organon, Porto Alegre, $n^{0}$ 53, julho-dezembro, 2012, p. 15-25 
artísticas e científicas e conscientes da necessidade de proteção dos direitos autorais contra usos comerciais indevidos, tornamos público alguns consensos quanto à necessidade de reforma da lei de direito autoral.

As novas tecnologias de informação e comunicação potencializaram o compartilhamento de conteúdos culturais. Tais práticas, sem envolver transações monetárias, trazem novas possibilidades de efetivação dos direitos à educação, à cultura, à informação e à comunicação.

Por outro lado, tem-se defendido que o controle da troca de arquivos na Internet seja feito por meio do monitoramento do cidadão no seu acesso à rede. Isso somente poderia ocorrer através da violação do direito à privacidade e com severas ameaças à liberdade de expressão e de comunicação. Entendemos que esse não é o melhor caminho, e que a reforma da lei deve ser realista face às novas tecnologias e práticas sociais. Destacamos que somos contra quaisquer usos comerciais da obra sem autorização de seu titular de direitos. Ressaltamos ainda a necessidade de reequilibrar a posição do autor frente aos intermediários culturais, de forma a potencializar as alternativas dos autores de produzir, distribuir e comercializar suas obras diretamente por meio das novas tecnologias da informação. Este equilíbrio conferiria maior autonomia e independência econômica aos autores, permitindo alargar as fronteiras ainda muito limitadas do mercado cultural.

Por fim, entendemos que é necessário harmonizar os interesses público e privado no acesso à cultura. Para isso, é necessário reequilibrar a tutela do direito individual de exploração da obra intelectual (cujo detentor freqüentemente não é o próprio autor da obra) com a tutela do direito coletivo de acesso à cultura, direito este tão fundamental quanto o direito autoral e cuja previsão encontra-se igualmente no corpo de nossa Constituição Federal. A criação é um fruto que tem origem no patrimônio cultural coletivo da sociedade e nesse sentido, sua fruição não pode ser restringida de forma desarrazoada.(Disponível em: $<$ http://stoa.usp.br/acesso $>$ )

\section{Recorte 2. Carta para Presidente e Ministra}

\section{:: Manifesto à Lei de Direitos Autorais ::}

Excelentíssima Presidenta e Ministra,

Venho através deste documento representar mais de mil profissionais da área de ilustração, que desenvolvem trabalhos de criação artística e intelectual e investem tempo e dinheiro se especializando para criarem imagens que compõem livros didáticos e literários, cartilhas, e as mais diversas peças gráficas. A ilustração vem se tornando cada vez mais o

Organon, Porto Alegre, nº 53, julho-dezembro, 2012, p. 15-25 
ofício de muitos. Uma profissão que existe há séculos e até hoje não recebe o devido reconhecimento. Para preservar os poucos direitos já adquiridos os profissionais desta área vêm se unindo e lutando por melhorias na profissão.

Nosso maior direito até então conquistado é o "Direito de Uso de Imagem" que se enquadra como "Direitos Autorais". Um direito que garante que nós, ilustradores, obtenhamos uma parcela ainda que mínima nas edições e reedições de projetos em que estivemos envolvidos e em que empenhamos todo o nosso poder de criação, desenvolvendo um trabalho artístico, intelectual e único. Direito esse que complementa nossa renda e assegura que recebamos por nosso trabalho enquanto este estiver sendo veiculado e gerando lucro para empresas, sejam elas editoras, revistas, jornais e etc.

A ilustração é uma linguagem que possui o poder de se comunicar com todos, despertando inúmeras interpretações e sentidos e estimulando a imaginação e a criatividade. Forma opinião e estimula o leitor, complementando e agregando valor aos textos. Por isso, os profissionais da área de ilustração precisam ser mais bem reconhecidos. A regulamentação da profissão é ainda o nosso principal objetivo e a nossa maior luta. E a manutenção do direito autoral é uma forma de fortalecer a nossa profissão, é conservando os direitos já adquiridos que alcançaremos e conquistaremos nossos maiores objetivos. Simplesmente retirar de nossas mãos esse direito é "pisar" em quem fomenta o mundo cultural e artístico do país, é não se importar com milhões de trabalhadores que dependem dessa profissão para sobreviver.

Lutar pelos nossos direitos autorais é uma maneira de defendermos o que é nosso e de nossos herdeiros, uma forma de garantir que o que foi criado através da nossa capacidade artística e intelectual seja valorizado enquanto estiver sendo usado. É nosso dever lutar para que não seja "jogado fora" tudo que foi produzido durante anos. Se vocês desejam acabar com este direito para unificar e democratizar toda a criação, o que será dos pensadores e criadores uma vez que essa é a sua profissão e precisam receber para isso? Se toda a criação for reutilizada de maneira arbitrária a qualidade despencará e os profissionais sumirão, tornando o Brasil um país pobre de sabedoria e intelectualidade. Precisamos conservar as criações e pensadores de todas as artes.

Neste caso defendo a área da ilustração e os profissionais ilustradores. Veja os livros que vocês compram para si mesmos, para seus filhos, sobrinhos, netos... Pense que em cada traço que ali está, há uma alma criativa por trás, que possibilita que vocês, leitores, entrem no mundo da imaginação e da fantasia. Quantas crianças e analfabetos podem "ler" 
os livros através apenas de suas imagens. Com certeza esse profissional precisa ser bem recompensado e motivado para continuar realizando seu trabalho com todo empenho possível e, para isso, seus direitos têm que ser "preservados" e não destruídos e descartados.

Atenciosamente,

Bruno Grossi (Begê Ilustrador) \& Diane Mazzoni Editores do Portal do Ilustrador (Disponível em http://www.portaldoilustrador.com/carta.pdf)

Recorte 3. Contra os desequilíbrios na Lei de Direitos Autorais

\section{E o conflito entre os direitos dos autores e os direitos do cidadão ao acesso às obras culturais?}

Nossa lei é uma das mais rígidas do mundo. Ela está extremamente desequilibrada do ponto de vista de quem consome obras protegidas. Direito autoral não é absoluto, está sujeito a limites, como o prazo de proteção. Mas toda legislação autoral tem uma parte que trata das limitações e exceções ao direito autoral, aquelas utilizações de obra que qualquer um pode fazer sem precisar de autorização prévia e sem ter que remunerar os detentores dos direitos. O nosso capítulo de exceções e limitações é muito restrito, ou seja, as nossas exceções estão em desacordo com nossa realidade social, econômica e cultural, tornando a lei rígida para o cidadão comum. Isso é outro problema que queremos discutir com a sociedade no Fórum. (Disponível em http://www.direitoacomunicacao.org.br)

Nesse jogo de formulações, formações discursivas se colocam em confronto, confronto este que se situa nos padrões de possibilidade de acesso a bens culturais. O elemento novo que aparece é o compartilhamento, sendo que, na formação discursiva representada pelo recorte 2 abaixo, não há caminhos construídos, sequer em construção, nessa direção, que não os padrões já estabelecidos antes do advento do espaço digital como mais uma possibilidade de circulação cultural.

\begin{tabular}{|c|c|c|}
\hline Recorte 1 & Recorte 2 & Recorte 3 \\
\hline $\begin{array}{ll}\mathrm{n} \text { e } c \text { e s s i d a d e } \\
\text { de promover } \\
\text { universalização } \\
\text { acesso }\end{array}$ & $\begin{array}{l}\text { Se vocês desejam acabar com este } \\
\text { direito [autoral] para unificar } \\
\text { e democratizar toda a criação, } \\
\text { o que será dos pensadores e } \\
\text { criadores }\end{array}$ & $\begin{array}{l}\text { Mas toda legislação } \\
\text { autoral tem uma parte } \\
\text { que trata das limitações } \\
\text { e exceções ao direito } \\
\text { autoral. nosso capítulo } \\
\text { de exceções e limitações } \\
\text { é muito restrito }\end{array}$ \\
\hline
\end{tabular}

Organon, Porto Alegre, n 53, julho-dezembro, 2012, p. 15-25 


\begin{tabular}{|c|c|c|}
\hline $\begin{array}{l}\text { compartilhamento de } \\
\text { conteúdos culturais. } \\
\text { efetivação dos direitos } \\
\text { à educação, à cultura, } \\
\text { à informação e à } \\
\text { comunicacão. }\end{array}$ & $\begin{array}{l}\text { Se toda a criação for reutilizada } \\
\text { de maneira arbitrária a qualidade } \\
\text { despencará e os profissionais } \\
\text { sumirão }\end{array}$ & $\begin{array}{l}\text { nossas exceções estão } \\
\text { em desacordo com } \\
\text { nossa realidade social, } \\
\text { econômica e cultural }\end{array}$ \\
\hline $\begin{array}{l}\text { conscientes da } \\
\text { necessidade de proteção } \\
\text { dos direitos autorais } \\
\text { contra usos comerciais } \\
\text { indevidos. } \\
\text { somos contra quaisquer } \\
\text { usos comerciais da obra } \\
\text { sem autorização de seu } \\
\text { titular de direitos. }\end{array}$ & $\begin{array}{l}\text { a manutenção do direito autoral } \\
\text { é uma forma de fortalecer a } \\
\text { nossa profissão, é conservando } \\
\text { os direitos já adquiridos que } \\
\text { alcançaremos e conquistaremos } \\
\text { nossos maiores objetivos }\end{array}$ & $\begin{array}{l}\text { Direito autoral não é } \\
\text { absoluto, está sujeito a } \\
\text { limites, como o prazo de } \\
\text { proteção. }\end{array}$ \\
\hline $\begin{array}{l}\text { Reequilibrar a posição } \\
\text { do autor frente } \\
\text { aos intermediários } \\
\text { culturais. Necessário } \\
\text { reequilibrar a tutela } \\
\text { do direito individual } \\
\text { de exploração da } \\
\text { obra intelectual } \\
\text { (cujo detentor } \\
\text { freqüentemente não é o } \\
\text { próprio autor da obra) } \\
\text { com a tutela do direito } \\
\text { coletivo de acesso à } \\
\text { cultura }\end{array}$ & $\begin{array}{l}\text { Precisamos conservar as criações } \\
\text { e pensadores de todas as artes }\end{array}$ & $\begin{array}{l}\text { Ela está extremamente } \\
\text { desequilibrada do } \\
\text { ponto de vista de } \\
\text { quem consome obras } \\
\text { protegidas }\end{array}$ \\
\hline
\end{tabular}

Os recortes 1 e 3 situam-se em uma formação discursiva tomada pela busca do equilíbrio (FD Equilíbrio). Assim, os sentidos que circulam nos dizem da universalização do acesso, do compartilhar, da necessidade de equilíbrio entre direitos, da revisão de partes da legislação autoral, da revisão das exceções e dos limites, sem negar a necessidade de proteger os direitos do autor em relação aos usos comerciais indevidos de sua obra.

No recorte 2, tem-se a formação discursiva centrada na propriedade e sua conservação, entendendo o que foge disso como arbitrário (FD Conservação).

Formulações que aparecem nos recortes 1 e 3 são apagadas na interpretação produzida no recorte 2 , indiciando que há sentidos outros 
já constituídos no processo histórico das relações sociais que fazem a interpretação, daqueles que se filiam à formação discursiva sintetizada no recorte 2, caminhar em uma determinada direção. Assim, o que aparece no recorte 3 como parte ( "...toda legislação autoral tem uma parte que trata das limitações e exceções... nossas exceções estão em desacordo com nossa realidade social..."), no recorte 2 aparece como todo ("Se vocês desejam acabar com este direito [autoral]... Se toda a criação for reutilizada de maneira arbitrária a qualidade despencará e os profissionais sumirão").

Isso nos remete a Pêcheux, para quem:

o sentido de uma palavra, de uma expressão, de uma proposição, etc, não existe 'em si mesmo' (isto é, em sua relação transparente com a literalidade do significante), mas, ao contrário, é determinado pelas posições ideológicas que estão em jogo no processo sócio-histórico no qual as palavras, expressões e proposições são produzidas (isto é, reproduzidas). (PÊCHEUX, 1988, p.160)

Se na formação discursirva aqui denominada Equilíbrio, o sentido de universalização desliza para compartilhamento e efetivação de direitos; na formação discursiva denominada Conservação, o sentido de universalização desliza para unificar e democratizar, sendo que o que parece estar em jogo, neste caso, são os sentidos de democracia e a relação com a propriedade, em que esta relação é tomada como ausência de regras e presença do arbitrário por aqueles que se filiam à formação discursiva Conservação.

\section{Gestão coletiva e efeitos do virtual}

Diversos têm sido os mecanismos de mobilização das categorias da sociedade que se posicionam nesse embate entre proteção e restrição, muitos na busca por um equilíbrio de direitos. Alguns desses mecanismos se viabilizam no espaço digital e isso traz efeitos importantes nos processos de formulação e circulação de sentidos. É o caso, por exemplo, das associações de proteção aos autores.

A própria quantidade de associações, no Brasil, criadas com o objetivo de proteger os autores apresenta sentidos importantes; compreender seus modos de formulação torna-se relevante nesse contexto, a fim de se Organon, Porto Alegre, nº 53, julho-dezembro, 2012, p. 15-25 
considerar como vem se configurando a gestão coletiva de direitos, no Brasil; em especial, quanto à relação que se estabelece entre Estado e associações. Destacamos aqui a análise realizada no site da ABDR - Associação Brasileira de Direitos Reprográficos - sociedade civil de natureza privada.

Enquanto resultados parciais, temos que os modos de formulação dos sites dessas associações marcam uma gestão administrativa de relações sociais, no âmbito da produção cultural brasileira, pautada, fortemente, pela ordem do estritamente burocrático e sem nenhuma participação do Estado. Os sentidos de proteção ao autor deslizam para classificação de usuários e determinação de quantia a ser paga pelo uso da obra; repressão a instâncias sociais tidas como infratoras da legislação vigente de direitos autorais; incentivos a modelos de arrecadação que, por meio de campanhas, como a da Pasta do Professor, situam o conhecimento não na ordem dos processos de construção de saberes, mas na ordem de aquisição fácil e rápida, por meio de capítulos isolados de algumas obras. É o sujeito enquanto usuário.

\section{Para um efeito de fechamento}

O processo de escrita do autor Pedro Nava, enquanto autor de um relevante trabalho memorialista, em comentário de Eneida Souza, remete-nos à questão da perda das origens dos sentidos que nos tomam no processo de textualização. E para nós este é um campo da memória não meramente da ordem da cognição, é da ordem do simbólico.

A prática quase obsessiva do desenho para reconstituição do passado não deve ser vista, porém, apenas como busca de verossimilhança. A escrita que nasce a partir do desenho, diz Souza, "é seqüestrada pela marca expressionista e particular de quem se vale do esquecimento como forma de inventar e de distorcer modelos". No instante em que ele escreve, as impressões do passado já estão filtradas pelo esquecimento e se reconstroem na sua condição de rasura e de falha, comprovando o “inevitável jogo entre memória e ficção". (SobreCultura 9, junho, 2012)

\section{BIBLIOGRAFIA}

ABREU, Ana Silvia Couto de. Políticas de autoria - entre regulação e falha. Rua [online], Campinas, n.15, v.1, p.1-8, 2009. Disponível 
em: <http://www.labeurb.unicamp.br/rua> . Arquivo acessado em 27 agosto de 2009.

Carta de São Paulo pelo acesso a bens culturais. [online] Disponível em: <http://stoa.usp.br/acesso $>$. Arquivo acessado em 19 de fevereiro de 2012.

Carta para Presidente e Ministra - Manifesto à Lei de Direitos Autorais. [online] Disponível em: <http://www.portaldoilustrador. com/carta.pdf> . Arquivo acessado em 19 de novembro de 2011.

ORLANDI, Eni Puccinelli. Interpretação - Autoria, leitura e efeitos do trabalho simbólico. Campinas: Vozes, 1996.

ORLANDI, Eni Puccinelli. Análise de Discurso: princípios e procedimentos. Campinas: Pontes, 2000.

PÊCHEUX, Michel. Semântica e discurso: uma crítica à afirmação do óbvio. Trad. Eni P. Orlandi et al. Campinas: Editora da Unicamp, 1988. PECHEUX, Michel. Estrutura ou acontecimento. Trad. Eni P. Orlandi. Campinas: Pontes, 1990.

ROMÃO, Lucília Maria Sousa. Exposições do Museu da Língua Portuguesa: arquivo e acontecimento e(m) discurso. São Carlos: Pedro \& João Editores, 2011.

SOUZA, Eneida Maria de. Seção Remate. Produção Sheila Kaplan. SobreCultura 9. Suplemento da Revista Ciência Hoje, junho, 2012. SOUZA, Marcos Alves. Contra os desequilíbrios na Lei de Direitos Autorais. [online] Disponível em: $<\mathrm{http} / /$ www.direitoacomunicacao. org.br> . Arquivo acessado em 12 de setembro de 2011.

Recebido em: 04/11/2012 Aprovado em: 12/11/2012

Organon, Porto Alegre, ํำ 53, julho-dezembro, 2012, p. 15-25 